\title{
Establishing Post Competency Indicator System for Staff of Grassroots Center for Disease Prevention and Control in China
}

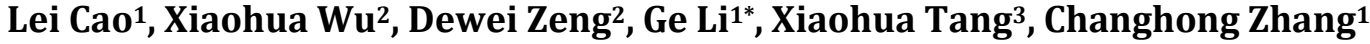 \\ ${ }^{1}$ School of Public Health and Management, Chongqing Medical University, Chongqing, China \\ ${ }^{2}$ Nana District Center for Disease Control and Prevention, Chongqing, China \\ ${ }^{3}$ Chongqing Traditional Chinese Medicine Hospital, Chongqing, China \\ Email: *geli@cqmu.edu.cn
}

How to cite this paper: Cao, L., Wu, X.H., Zeng, D.W., Li, G., Tang, X.H. and Zhang, C.H. (2019) Establishing Post Competency Indicator System for Staff of Grassroots Center for Disease Prevention and Control in China. Open Journal of Social Sciences, 7, 291-300.

https://doi.org/10.4236/jss.2019.710024

Received: September 25, 2019

Accepted: October 21, 2019

Published: October 23, 2019

Copyright $\odot 2019$ by author(s) and Scientific Research Publishing Inc. This work is licensed under the Creative Commons Attribution International License (CC BY 4.0).

http://creativecommons.org/licenses/by/4.0/

\begin{abstract}
With the economic and social development, the public's demand for public health services has increased in China, and the functions of the Center for Disease Control and Prevention have also been transformed. While most Centers for Disease Control and Prevention currently have some degree of reform in their staffing and distribution systems, there have been few changes in the appointment and selection of their staff. Through literature review, this article will demonstrate the importance of establishing the scientific and effective competency indicator system for grassroots public health practitioners, so as to provide reference for human resource management of district and county level CDC.
\end{abstract}

\section{Keywords}

Center for Disease Control and Prevention, Competency, Human Resources, Public Health

\section{Introduction}

The Center for Disease Control and Prevention (CDC) is the main body of China's public health system, especially the district- and county-level Center for Disease Control and Prevention. Since the reform and opening-up, China's public health has made significant progress. Between 1949 and 2010, life expectancy has risen from 35.0 years to 74.8 years. Especially after SARS in 2003 [1], the national government increased the input of human, material and financial resources to the district and county level CDC, so that the grassroots CDC ushered 
in rapid and systematic development. However, the development of human resources in China's grassroots CDC has been slow. According to relevant studies, the human resources research of CDC in China is still in the initial stage, and there is no scientific experience to follow, let alone a systematic way to promote it [2]. In the grassroots CDC, the rational allocation of human resources not only affects the smooth realization of disease prevention and control measures, but also the basic conditions for the sustainable development of public health. Therefore, this article will explain the importance of establishing the post competency indicator system for staff engaged in grassroots disease prevention and control work in China through literature review, with the purpose of providing a new means for human resource management and talent team construction of grassroots CDC.

\section{Research Methods}

The literature review was carried out through scientific databases, including PubMed, Web of Science, China National Knowledge Infrastructure (CNKI), etc.; using keywords: Competency, Center for Disease Control and Prevention, $\mathrm{Hu}$ man Resources, Public Health. In order to select suitable articles, the literature meeting the following conditions was included: 1) the literature related to human resource management of the Chinese Center for Disease Control and Prevention; 2) literature on job or post competency of CDC and public health related personnel. Exclusion criteria: 1) studies not related to job competency or human resources of CDC; 2 ) the study subjects are not $\mathrm{CDC}$ and public health related staff. More than 121 relevant articles at home and abroad were included. However, in this article, in order to better illustrate the importance of the establishment of the competency indicator system for the staff of grassroots CDC to be competent for their job, some relevant articles beyond the inclusion criteria were included.

\section{The Importance of Establish Competency Indicator System for China's Grassroots CDC}

\subsection{Current Challenges of Human Resource Management in District and County CDC}

In the 2000 WHO health system performance evaluation, China ranked fourth in the ranking of fairness [3]. At present, the two-child policy is opening up, the high incidence of chronic non-communicable diseases, and the severe population ageing trend have put tremendous pressure on the development of grassroots public health services in China. Similarly, these new public health service demands have brought new requirements to the human resources management of China's grassroots CDC. However, the grassroots CDC is still faced with various unbalanced problems [4], such as imperfect public health policy system, insufficient government financial input, unbalanced allocation of health resources, and insufficient government attention to public health [5]. These prob- 
lems not only seriously affect the development of national basic public health services, but also cause many adverse effects on the construction of talent team of grassroots CDC, For example, the staffing of departments is unstable, the mobility of personnel is increasing, the distribution between regions is large, and the quality of the staff is low, etc. [6].

Through literature research, it is found that human resource management in China's district and county level Centers for Disease Control and Prevention currently faces several problems. First, the total amount of human resources is insufficient and the turnover rate of personnel is high. By the end of 2013, the total number of personnel in China's CDC was 194,371, accounting for only $2.1 \%$ of the total number of people in all health care institutions [7]. From 2010 to 2014, the total number of people in the CDC has decreased year by year [8]. However, during the same period, the total number of health workers nationwide increased from 8,207,500 to $1,023,400$ [2]. And the CDC suffers from serious staff turnover in China. The average annual outflow rate of county-level CDC personnel in China from 2012 to 2015 was as high as 2.27\% [9]. The outflow of personnel is mainly the outflow of professional and technical personnel, and the management personnel flow in. At present, China has a high incidence of public health emergencies and emerging infectious diseases. And the grassroots CDC is responsible for many tasks such as health checkup, planned immunization, and disease surveillance. Therefore, the shortage of human resources will seriously affect the development of grassroots public health services in China. Second, the staffing structure of CDC has improved, but the aging trend is still very serious. Some studies have shown that the education level, professional title ratio and comprehensive quality of human resources in CDC have been improved, but the proportion of postgraduates with high academic degrees is still low. The county-level CDC is mainly based on undergraduate and junior college degrees [10]. In addition, $\mathrm{Hu}$ longjun et al. surveyed 257 county-level $\mathrm{CDC}$ in 9 provinces of China, and found that in the CDC, people aged $30-35$ accounted for the most. The proportion of people under 35 years old has been declining, while the proportion of people between 35 and 50 years old and over 50 years old has been increasing year by year [11], which indicates that China's county-level CDC has an aging trend, and the sustainable development of human resources has been greatly challenged. Third, there is a shortage of professional and technical personnel. The government stipulates that the professional and technical personnel of China's CDC should not be less than $85 \%$ of the total amount, and the health technicians must not be less than 70\% [12]. In 2015, a survey by Chinese National Health Commission on 31 provincial-level CDC found that only 17 provinces have more than 85 percent of the professional and technical personnel, and only 24 provinces have 70 percent of the health technical personnel [13]. From 2016 to 2017, the professional and technical personnel of CDC accounted for $82.05 \%$ and $82.22 \%$ respectively, and the health technicians accounted for $74.34 \%$ and $74.51 \%$ respectively [14]. The proportion of health technicians is up to standard, while the proportion of professional and 
technical personnel is not up to standard. Fourth, the regional distribution of human resources is unbalanced. The number of CDC institutions in the eastern region is higher than that in the western region [7]. In the central and western regions, especially at the grassroots CDC, the total number of personnel is small, low educational background, low professional title, serious aging, lack of public health professionals and other problems are more common [15]. Although the country has taken some measures in recent years to strengthen the capacity building of disease control system in the western region, and some achievements have been made, the development of the western region is still slow, and there is still a big gap between the eastern and western provinces. Therefore, the Chinese government proposed in the document "medium- and long-term talent development plan for medicine and health (2011-2020)" that it should strengthen the management of public health talent team [16], especially improve the staff management and team building of grassroots centers for disease control and prevention.

\subsection{What Is the Post Competency and Its Function}

Competency is the knowledge, skill, ability, trait or motivation that connects people directly or indirectly to work or work performance or other important outcomes in life. It can be reliably measured or counted, and can clearly distinguish excellent performance and general performance. In 1973, proposed by David M. [17]. He believes that academic performance and intelligence can't predict a person's career or life achievement. Those who are good at work are because they have self-discipline, initiative, responsibility and other quality and behavioral characteristics, which make them achieve excellent achievements. Therefore, he proposed the post competency model method, recommended the use of competency to test the staff, and search for the key qualities and ability characteristics of the outstanding employees. Competency model refers to the integration of competency for a specific role and specific performance requirements (knowledge, skills, motivation, traits and self-concept), it can specify what knowledge, skills, abilities and qualities are required to meet the responsibilities of the position [18]. The competency model not only improves the working level of a specific position, but also be used for employee selection, training, and performance evaluation, etc. It is considered as a universal tool of human resource management. Research shows that the following three important characteristics of competency are recognized by experts [19]. Firstly, it is closely related to the work position and influenced by the working environment and working conditions and the position characteristics. It is dynamic and can be changed in real time. Secondly, it is closely related to the work performance of employees. And it can distinguish the high performers from the average performers in the job and predict the future work performance of employees. Thirdly, it can be measured stably. Studies have shown that the research object of competency is not only limited to individuals, but also can be a team composed of several personnel. That is, there are not only individual post competency characteristics, but also core 
competency characteristics of the organization [20].

According to the correlation analysis of human quality and disease prevention and control work completion degree [21], it is found that workers with high quality have higher work completion degree, while those with low quality have lower work completion degree. However, in the past, the management and selection of CDC personnel paid more attention to the professional knowledge, qualification and performance level of employees, and paid less attention to the internal personal characteristics of employees' work motivation and values. And the current selection of personnel in China's CDC still lacks quantitative standards that are consistent with job requirements and lacks scientific performance appraisal tools. These shortcomings in human resource management often lead to the consequences of staff and job mismatches in the selection of personnel at the grassroots disease prevention and control center. The rational allocation of human resources and scientific and effective human resource management are the key factors and basic conditions for sustainable development of district and county CDC, as well as an important means to improve the working ability of grassroots public health workers. Therefore, it is recommended to introduce post competency into the human resources management of grassroots CDC.

\subsection{Common Methods for Establishing Competency Model}

There are many ways to establish a job competency model at home and abroad. The most commonly methods include Delphi method, Behavioral Event Interview (BEI), Analytic Hierarchy Process (AHP), Exploratory Factor Analysis method (EFA), questionnaire survey method and other methods. And the post competency model is mainly divided into the onion model and the iceberg model. Generally speaking, in the field of public health [22], researchers choose to combine various research methods to establish competency model according to general competency models and specific job requirements. For example, Chang wenjuan et al. combined questionnaire survey with exploratory factor analysis to study the post competency model of Chinese public health physicians [23]. What's more, in order to comprehensively cover all the post competency indicators required for a certain position, the researcher needs to clarify all the basic work requirements for the post firstly. And on the premise of completing the basic work, it is necessary to find more excellent competency indicators to make the work better, that is, the benchmark competency and the identification competency.

\subsection{Competency Research Is Widely Used in Society}

Since Professor McClelland proposed the theory of competency, the research on the competency model has caused a boom in Western countries, especially in developed countries. The research on the competency model is very important, and the research system is very mature. The competency model is mainly applied to the human resources management of the company. According to rele- 
vant research, the selection, training and salary design of talents based on competency can improve the efficiency of the use of units and reduce the turnover rate of talents [24]. The first competency model was applied to the selection of junior diplomats from the U.S. Department of Foreign Affairs, and eventually selected a group of outstanding diplomats with excellent competency. The University of Michigan in the United States conducted research on tens of thousands of HR workers nationwide in 1988, 1992, 1997, and 2002, and obtained a competency model for HR [25]. However, China did not begin to pay attention to competency until the 1990s. The research is still in its infancy [26], but the research on competency is paying more and more attention. In terms of research scope, it is focus on the human resources management system such as senior managers, marketing personnel and technical personnel of the company.

\subsection{Competency Research in the Health Care System}

Now, competency research has gradually entered the field of Clinical Medicine and Public Health. NHCL has established NCHL competency model for the managers of American health care institutions [27]. In 2010, the United States conducted a study on the competency characteristics of occupational health nurses [28]. Research on China's health care system competency can be traced back to 2001. Although the current research on competence in the medical field is still in its infancy, in recent years, the application of competency models in the Chinese medical field has become more and more extensive, mainly focusing on the executives of medical institutions [29], clinicians [30] and nursing staff [31]. At present, China's grassroots teaching base at the general practitioners has used the basic characteristics of general practitioners' competence established by the World Family Doctors Organization (WONCA) in Europe in 2005, which provides good advice for the general practitioner's diagnosis, treatment and community teaching [32]. In addition, competency research was introduced in the maternity and gynaecology nurse in China, and the Exploratory Factor Analysis (EAF) method was used to establish the competency model of obstetric nurses, which provided a scientific basis for their selection and evaluation [33].

\subsection{Research of Post Competency Model in Public Health}

The research on the post competency model in the field of public health is very mature abroad, and it is very useful for the study of the competency model of China's public health field, especially the grassroots Center for Disease Prevention and Control. In recent years, according to the actual situation of each country, the United States, Japan, Europe and other countries have established a series of competency models for practitioners in public health work, such as public health nurses [34], emergency response personnel [35], as well as public health nutritionist [36], they also established the academic competence for the Master of Public Health and the Doctor of Public Health. In 2008, the American Association of Schools of Public Health established the competency model for Public 
Health Doctors through Delphi method and expert group scoring method, which includes 54 competency characteristics in 5 disciplines [37]. In the same year, the European Public Health Association (ASPHER) also established a doctoral competency model for public health, with seven categories [38]. These studies have received wide attention from peers. In 2009, some experts in China proposed to introduce the post competency model into the human resources management of the CDC [39]. In recent years, many Chinese experts and scholars have devoted themselves to the study of the competency in the field of public health. They respectively established the competency models for the emergency response personnel in public health emergencies [40], director of the Center for Disease Control and Prevention [41], and public health physician [23]. In particular, Chang Wenjuan et al. [23] established a post competency model for public health physician. This model includes personal characteristics, clinical medical knowledge, preventive medical knowledge, public health work skills, English ability, and media coping skills in six dimensions, and defines the post competency of public health doctors in China to be qualified for this post. By literature review and Delphi method, Sun guangning et al. [40] established a post competency model for public health emergency personnel of district and county CDC, including four dimensions: personal characteristics, emergency knowledge theory, emergency skills and basic knowledge. The emergency personnel competency model has provided a basis for the selection of public health emergency response personnel in grassroots CDC. These studies are of great referential significance to the establishment of post competency indicator system for the staff at district and county level CDC.

However, it is still difficult to complete competency research in Chinese grassroots CDC. Currently in China, research on the competence of clinical medicine and nursing staff is very rich, but little research has been done on the competence of public health workers [42]. And the research time of this kind of research in the field of public health in China is relatively short and most of them focus on the theoretical area. Even if the competency model is established, there is still a lack of evaluation on the effect judgment of practical application [42]. In addition, the research methods of this kind of research have high requirements on the professional quality and ability of researchers and subjects, For example, the Delphi method requires that the research subjects participating in the study have high experts authority and are familiar with the research, and the Behavioral Event Interview method requires that the researchers have strong combing ability and coding ability for the research content. However, in view of the benefits that job competency brings to the human resource management of grassroots CDC, it is still suggested to integrate the post competency model into the human resource management of district and county level CDC.

\section{Conclusion}

In summary, the reform of human resources management in China's grassroots 
CDC is imminent, and the research on post competency is very extensive and widely used at home and abroad. Therefore, it is of great significance to introduce the post competency model into the reform of human resource management in China's grassroots CDC. Establishing the competency indicator system for the practitioners who engaged in the public health work at the district and county level CDC in China, which can not only clarify the knowledge and skills required by the staff to be competent for the essential public health service, but also clarify the internal qualities that the practitioners need in the grass-roots disease control work, and it will be helpful to the talent recruitment training and management of grassroots CDC.

\section{Acknowledgements}

This work was supported by the Science and Health Joint Medical Research Project in Chongqing, China (Grant number 2018MSXM095, 2018). And we thank the following persons: Professor Ge Li and Professor Hong Xu (both from Chongqing Medical University); Director Jiang Long and Director Yifu Xiao (both from Chongqing Centers for disease Control and Prevention).

\section{Conflicts of Interest}

The authors declare no conflicts of interest regarding the publication of this paper.

\section{References}

[1] Li, X.Z., Fan, D. and Qun, L. (2012) Analysis of Human Resource Development in China Center for Disease Control and Prevention. China Preventive Medicine, 5, 399-400.

[2] Yan, K., Li, C.C. and Ni, J.W. (2017) China's Disease Prevention and Control of Human Resources Present Situation and Research Progress. Chinese Journal of Public Health Management, 3, 48-52.

[3] Shun, G.G., Qiao, N. and Yang, L. (2007) Discussion on the Development of Public Health in China. Chinese Health Quality Management, 14, 75-77.

[4] Juan, W.Z., Peng, G.Z. and Jie, W.T. (2017) Analysis of Equity Index of Human Resource Allocation in Chinese Disease Prevention and Control Institutions. Chinese Journal of Public Health, 33, 1092-1095.

[5] Jin, S.W. (2008) Current Situation and Development Measures of Public Health in China. Medical Information, 21, 615-617.

[6] Le, Z. (2013) The Center for Disease Control and Prevention of Human Resources at the County Level Analysis of Present Situation and Change. Doctoral Dissertation, Fudan University, Shanghai.

[7] Qing, X.Z., Yan, L. and Lei, S. (2015) Analysis of Human Resources in Chinese Disease Prevention and Control Institutions. Chinese Journal of Public Health Management, 3, 332-334.

[8] Chao, Y.X., Dan, Y.S. and Hao, C. (2017) Analysis of Changes in Chinese Disease Prevention and Control Institutions and Personnel from 2010 to 2014. Chinese Journal of Public Health Management, No. 1, 50-52.

[9] Yin, H. (2017) Investigation and Study on the Current Situation of Staff Outflow in 
County Center for Disease Control and Prevention from 2012 to 2015. Economic Engineer, 337, 246-247.

[10] Yang, Y., Wang, S.W. and Jie, Y.Z. (2013) Analysis of the Current Situation of Human Resources in the National Center for Disease Control and Prevention. China Digital Medicine, 10, 109-111.

[11] Jun, L.H., Shui, F.C. and Mei, S. (2017) Analysis of Human Resources Changes in 257 County-Level Centers for Disease Control and Prevention in 9 Provinces. Medicine and Society, 30, 5-7.

[12] Chinese National Health Commission (2014) Notice of Guidance on the Personnel Establishment Criteria of the Centers for Disease Control and Prevention. http://www.epiman.cn/thread-137851-1-1.html

[13] Wei, Z.C., Han, L. and Qing, X.Z. (2018) Analysis of Human Resources Situation of National Provincial Centers for Disease Control and Prevention. Chinese Journal of Public Health, 34, 96-97.

[14] National Health Commission (2018) China Health Statistics Yearbook. 65-66. http://www.yearbookchina.com/navibooklist-n3018112802-2.html

[15] Di, C.L., Shan, X.F. and Lin, F. (2006) Human Resource Analysis of County Centers for Disease Control and Prevention in Central and Western of China. Chinese Journal of Public Health, 22, 1153-1154.

[16] Chinese Ministry of Health (2011) Medium and Long-Term Talent Development Plan for Medical and Health (2011-2020). http://www.xtzy.com/html/73034.html

[17] Horton, S. (2000) Introduction-The Competency Movement: Its Origins and Impact on the Public Sector. International Journal of Public Sector Management, 13, 306-318. https://doi.org/10.1108/09513550010350283

[18] Feng, X. (2012) Construction of Human Resource Performance Management System: A Perspective of Competency Model. Enterprise Economy, 1, 68-71.

[19] Li, L. (2011) Application of Post Competency Model in Talent Management. Enterprise Herald, 5, 208-209.

[20] Zhang, H.A. (2003) The Construction and Improvement of Job Competency Model. Economic and Management Research, 4, 42-45.

[21] Mei, H. (2015) Analysis and Countermeasures on the Current Situation of Talent Tam Construction in Public Health Field under the New Situation. Chinese Journal of Health Professionals, No. 2, 78-82.

[22] Lei, S., Mei, C.Y. and Kang, Z.C. (2017) Review and Reference of Competency Models in Public Health Field at Home and Abroad. Chinese Journal of Public Health Management, No. 2, 43-45+62.

[23] Juan, W.C., Xin, Z. and Hua, L.F. (2017) Construction of Competency Model for Public Health Practitioners in Tianjin. Chinese Journal of Modern Medicine, 19, 1-5.

[24] Wang, C. (2004) Who Can Be Competent, Competent Model and Use. China Financial Economics Press, Beijing.

[25] Ulrich, D. (2007) Human Resource Competency Study. Michigan Ross School of Business, Michigan.

[26] Si, W.C. and Ming, Z.S. (2010) Research on the Competency Model of China's Best Employer Human Resources Director. Chinese Journal of Management, 7, 1308-1315.

[27] Ru, W.H., Yun, X.C. and Jie, Y.H. (2017) Research and Development of the Competency Model of American Health Institution Administrators. Chinese Hospitals, $21,78-80$. 
[28] Kono, K., Goto, Y. and Hatanaka, J. (2017) Competencies Required for Occupational Health Nurses. Journal of Occupational Health, 59, 562-571. https://doi.org/10.1539/joh.16-0188-OA

[29] Fei, M.D., Juan, Z.C. and Zhen, F.S. (2011) Research on the Competency of Middle Management Cadres in the Health Administrative Department of Panzhihua City. China Health Care Management, No. S1, 91-94.

[30] Jiao, J.L., Lei, J.Y. and Tao, S. (2013) Research on the Construction of General Practitioner Competency Model Based on Exploratory Factor Analysis. Chinese Journal of General Practice, 16, 3659-3661.

[31] Yao, H., Le, J.H. and Lei, Y. (2016) Construction of Competency Model for Head Nurse in China. Nursing Journal of PLA, 33, 28-31+35.

[32] Ying, Z.F. and Yue, J. (2016) Application of European Post Competency Model in Training of Grassroots Practice Base. Continuing Medical Education, 30, 17-19.

[33] Jin, L., Shuai, L.J. and Bei, D. (2017) Construction of Competency Model for Obstetrics and Gynecology Nurses Based on Exploratory Factor Analysis. Journal of Nursing Administration, 17, 81-84.

[34] Saeki, K., Izumi, H., Uza, M. and Murashima, S. (2007) Factors Associated with the Professional Competencies of Public Health Nurses Employed by Local Government Agencies in Japan. Public Health Nursing, 24, 449-457. https://doi.org/10.1111/j.1525-1446.2007.00655.x

[35] Gebbie, K. and Merrill, J. (2002) Public Health Worker Competencies for Emergency Response. Journal of Public Health Management and Practice, 8, 73-81. https://doi.org/10.1097/00124784-200205000-00011

[36] Jonsdottir, S., Hughes, R. and Thorsdottir, I. (2010) Consensus on the Competencies Required for Public Health Nutrition Workforce Development in Europe-The Jobnut Project. Public Health Nutrition, 14, 1439-1449. https://doi.org/10.1017/S1368980010000625

[37] Calhoun, J.G., Mcelligott, J.E. and Weist, E.M. (2012) Core Competencies for Doctoral Education in Public Health. American Journal of Public Health, 102, 22-29. https://doi.org/10.2105/AJPH.2011.300469

[38] Foldspang, A. (2008) Editorial: Developing the Public Health Workforce in Europe: Association of Schools of Public Health in European Region (ASPER). Journal of Public Health Policy, 29, 143-146.

[39] Zhi, P.X., Lei, L. and Yi, L. (2009) Human Resource Management in Disease Control System Using Competency Model. Modern Preventive Medicine, 36, 1084-1085.

[40] Ning, G.S., Bin, X. and Jian, Z. (2016) Study on the Evaluation Index System of Health Emergency Personnel Competency in County CDC. Modern Preventive Medicine, 44, 3154-3158.

[41] Peng, G.Z., Ran, R. and Juan, Z.C. (2009) Construction and Application of Competency for the Post of Director of County-Level Centers for Disease Control and Prevention. Chinese Health Policy Research, 2, 52-56.

[42] Zhu, L.X., Xue, S.L. and Yong, C. (2006) The Health Human Resource Investment and Problems. Chinese Health Economy, 25, 30-33. 